\title{
CONCEPTUAL PRINCIPLES OF PROVIDING THE INFORMATION SECURITY OF THE NATIONAL ECONOMY OF UKRAINE IN THE CONDITIONS OF DIGITALIZATION
}

\section{Svitlana Onyshchenko}

Department of Finance, Banking and Taxation, Institute of Finance, Economy and Management, National University "Yuri Kondratyuk Poltava Polytechnic", Poltava, Ukraine

\author{
Alina Yanko \\ Department of Computer and Information Technologies and Systems, Institute of Information \\ Technologies and Mechanotronics, National University "Yuri Kondratyuk Poltava \\ Polytechnic", Poltava, Ukraine \\ Alina Hlushko \\ Department of Finance, Banking and Taxation, Institute of Finance, Economy and \\ Management, National University "Yuri Kondratyuk Poltava Polytechnic", Poltava, Ukraine

\section{Svitlana Sivitska} \\ Department of Finance, Banking and Taxation, Institute of Finance, Economy and \\ Management, National University "Yuri Kondratyuk Poltava Polytechnic", Poltava, Ukraine
}

\begin{abstract}
Since the beginning of the development of digital information processing and management tools, speed (performance) and reliability (fault tolerance) have become of their main characteristics. In this article the research aims at strengthening the national security of the state economic in the information sphere on the basis of ensuring the reliability, confidentiality, integrity and availability of state information resources, information with limited access, including the one that circulating on the objects of financial information infrastructure in the conditions of information and hybrid wars.

Modern methods and means of information and communication and digital technologies cannot fully ensure productive and reliable processing of ever-growing arrays of information in the economy. Digitization processes require a significant increase in security and reliability of economic data processing, which is possible through the use of new machine arithmetic, as the existing positional binary number system has shortcomings. In this aspect, the non-positional number system in the residual classes opens wide opportunities for building not only new machine arithmetic, but also a fundamentally new circuit implementation of computer systems, which in turn
\end{abstract}


Conceptual Principles of Providing the Information Security of the National Economy of Ukraine in the Conditions of Digitalization

significantly expands the use of machine arithmetic and is reliable because existing threats are not adapted to non-positional code structures and don't pose any threat to the economic data.

This article focused on the issue of reliability, namely: fault tolerance and survivability of computer systems for economic data processing (CSEDP) as one of the criteria for assessing information security, by forming the problem of optimal redundancy in the system of residual classes (SRC).

Key words: computer systems for economic data processing, fault tolerance, informational security, non-positional number system, system of residual classes.

Cite this Article: Svitlana Onyshchenko, Alina Yanko, Alina Hlushko and Svitlana Sivitska, Conceptual Principles of Providing the Information Security of the National Economy of Ukraine in the Conditions of Digitalization, International Journal of Management, 11(12), 2020, pp. 1709-1726.

http://iaeme.com/Home/issue/IJM?Volume=11\&Issue $=12$

\section{INTRODUCTION}

A characteristic feature of an digital society is the development and use of new, progressive information technologies based on the widespread use of super productive and reliable computer systems (CS) [1]. The development and improvement of over-productive and reliable CS is a strategically important and topical issue and is under the special control of the heads of states and governments of the advanced countries of the world.

The key trends in the world economy indicate that the rapid development of IT technologies, globalization and the growth of instability that characterize modern global macroeconomic processes, contain a number of risks and threats to the national economy. Regulation of market processes in the economy of Ukraine is due to a number of factors, including unstable foreign economic conditions, unfavorable investment climate, low growth of aggregate demand in the domestic market, a negative trade balance [2]. Economic development and competitiveness of the country are possible only if a combination of modern technologies, knowledge-intensive and resource-saving industries with a variety of promising forms of information management mechanisms. The above determines the relevance of the formulation of the conceptual foundations of information security of the national economy in digital conditions.

Existing concepts of information security of the national economy do not fully correspond to the current conditions in Ukraine, due to the digitalization of economic processes both at the national and global levels. Therefore, it is necessary to develop fundamentally new approaches to information security of the national economy, which should be based on conceptual provisions that are more appropriate to the trends of rapid development of the information economy, including an institutional approach to state regulatory policy based on national security.

From a technical point of view, the results conducted in recent years by various groups of researchers to find ways to increase the noise resistance of CS, methods of organizing an effective system for detecting and correcting errors and building highly reliable computing systems without essential increase in working frequencies of elements and complication of the hardware part of CS.

It is also possible to increase the reliability of processing integer data based on the use of new machine arithmetic. In the positional number system (PNS), the execution of an arithmetic operation involves the sequential processing of the digits of operands according to the rules determined by the content of the operation, and can not be completed until the values of all 
intermediate results are sequentially determined taking into account all the connections between the digits. Thus, PNSs, in which information is presented and processed in modern computers, have a significant drawback - the presence of inter-bit relations, which impose its imprint on the reliability of implementing arithmetic operations, the occurrence of a single error can lead to a block of errors and to incorrect decision making [3]. Therefore, it is natural to look for possibilities of using such arithmetic, in which there would be no queuing connections. In this regard, the system of calculus in the residual classes draws attention to itself. SRC has a valuable properties which offer wide opportunities for constructing not only new machine arithmetic, but also a fundamentally new scheme for the implementation of CS, which in turn significantly expands the use of machine arithmetic. The joint use of properties SRC determines the presence in the CS simultaneously three main types of redundancy: structural, informational and functional, which is one of the elements of information security and data reliability and which have no analogues in thePNS [4].

There is one condition for the effectiveness of the use of SRC as a number system CS, designed to implement integer arithmetic operations of addition, subtraction and multiplication of numbers in the positive numerical range, significantly increases the reliability of solving problems of a certain class [5].

Today, there are a number of areas of science and technology, where there is a need for fast, reliable and high-precision integer arithmetic calculations of this class: liner programming, neurosystems and neural network data processing systems, satellite systems, economics, tasks for military purposes, digital signal processing and etc.

\section{LITERATURE REVIEW}

In today's conditions, the problems of providing the resilience of the national economy to the negative impact of a wide range of threats in the context of state security are widely relevant in the works of domestic scientists, in particular O. Baranovskoho, Z. Varnaliia, O. Vlasiuka, V. Heitsia, A. Halchynskoho, Ya. Zhalila, M. Yermoshenka, S. Kirieieva, V. Kyrylenka, V. Martyniuka, V. Muntiiana, S. Pyrozhkova, V. Predborskoho, A. Sukhorukova, V. Shlemka, N. Yurkiv and many others.

Thus, O. Baranovskyi in his research reveals the genesis of security from the standpoint of philosophical, sociological and religious perception. In the works of Z. Varnalii [6] the theoretical principles of economic security are considered, the mechanism of its provision is substantiated. An important contribution is the detailing of security threats to the national economy and ways to prevent them. V. Heiets research [7] is devoted to the problems of ensuring economic security. The developed indicators of economic security of Ukraine deserve special attention. In the works of N. Yurkiv [8] the theoretical and methodological principles and applied means of achieving security of the real sector of the economy are revealed.

Noting the role and importance of existing research on the security of the national economy, it is clear that in the context of digitalization, one of the most pressing issues is the problem of information security.

The results of research in the field of creating reliable computer data processing systems by well-known authors (Valakh M., Svoboda A., Sabo N., Aksushskyi I.Y., Yuditskyi D.I., Glushkov V.M., Torgashov V.A., Amberbaev V.M., Kolyada A.A., Shimbo A., Paulier P., Thornton M.A., Dreschler R., Miller D.M., and others) showed that the features of the structure and principles of operation of the computer data processing systems in the SRC contribute to the development of effective and optimal methods of redundancy (reservation), which have no analogues in the positional number system and significantly increases the efficiency of control, diagnosis and correction of data presented in SRC. 
Conceptual Principles of Providing the Information Security of the National Economy of Ukraine in the Conditions of Digitalization

In recent years, the following reliable computer data processing systems have been developed in the SRC: On-board computer Star (USA); specialized DFT processors (USA, South Korea); a number of military specialized on-board computers (USA, Japan); specialized DSP processors (USA); Sprint Computers for Robotics (USA, Japan); in the Chinese company "Tpv Display Technology (Wuhan, China) Co., Ltd" in the development and implementation of a wireless sensor network monitoring system for industrial equipment in the manufacture of monitors; at the enterprise "Relcom-Podillya Ltd." in developing the system of video surveillance on the basis of wireless multimedia sensor networks; at "Cypress Semiconductors Corporation" in developing hardware software for CY8CKIT-050 PsoC 5 and CyFi (CYRF7936) modules that can be used in wireless sensor networks [6].

In the context of digitalization, it has become important to develop a reliable and faulttolerant CSEDP to ensure information security of the national economy of Ukraine.

\section{MATERIALS AND METHODS OF STUDY}

Of course, for the protection economic data information to be comprehensive and take into account all the criteria for assessing information security, it is necessary to consider and solve a number of tasks: to analyze the state of information security in modern CS and networks; substantiate the requirements and directions of development of CSs and networks in order to increase the security of information in CSs and networks based on the development of optimal redundancy of economic data; to obtain new scientific and scientific and technical achievements in the field of application of new machine arithmetic, such as non-positional number system in SRC; to increase the reliability of economic data processing in CS and networks, including cryptographic data transformations, to carry out the formation and processing of new types of code-signal structures - data carriers with the necessary properties and methods of their processing.

Obviously, it is impossible to consider all the above problems within the article. Therefore, it was decided to dwell in more detail on the issue of reliability, namely: fault tolerance and survivability of the CSEDP as one of the criteria for assessing information security, by forming the problem of optimal redundancy in SRC.

The concept of fault tolerance is closely related to the concept of reliability CSEDP. By fault tolerance, in accordance with DSTU 2506-94, we will understand the property that was put in place when designing CSEDP, which allows you to maintain its full or partial performance in the presence of CSEDP elements in a state of failure. Fault tolerance is the most important characteristic of CSEDP. For CSEDP, operating in the binary positional number system, methods of improving reliability and fault tolerance are based on the use of various types of redundancy: structural, informational, temporal, load and functional. The basic idea of the organization of the fault-tolerant operation of CSEDP is as follows. Due to the existing (or artificially introduced) redundancy, the failed block of CSEDP is first determined, and then the failure (malfunction) is eliminated by excluding this block from the process of functioning. It is necessary to once again emphasize that for real-time CSEDPs the process of detecting failures (malfunctions) and eliminating them should be done without interrupting the computational process, i.e. in the process of functioning.

The results of studies of improving the efficiency of real-time CSEDPs, obtained both in Ukraine and abroad, have shown that existing methods for improving performance, reliability, resiliency and survivability of operation based on the use of binary PNS do not always fully satisfy increasing requirements for special-purpose information processing systems. This circumstance necessitates the formulation of concepts, the search for non-traditional ways and 
methods to improve the performance, reliability, failure resistance and survivability of CSEDP by objects of critical application, operating in real time.

There are two main methods for increasing the reliability of CSEDP operating in the PNS: improving the reliability of individual logic elements (using the new element base) and introducing various types of redundancy (using different types of redundancy affecting both the design and functional reliability of CSEDP). Since the reliability of logical elements of CSEDP is determined by the level of technology development, it is obvious that the introduction of redundancy in the use of any element base is the most effective way to increase the reliability of CSEDP. The variety of conditions and rigidity requirements (the need to ensure a high degree of computational accuracy, high performance and fault tolerance of operating CSEDP in real time, operational recoverability of the apparatus after failures, etc.) imposed on the mode of operation and operation of directing CSEDPs, do not always allow the use of time and information backup. As a result, one of the effective practical methods of increasing the reliability of CSEDPs, functioning in the PNS, is structural redundancy, for example, at the level of a triple majority structure. However, the use of structural redundancy in the PNS complicates the structure of the computing complex, increases its energy consumption, leads to an increase in mass, size and other characteristics, which ultimately increases the cost of its creation and operation, as well as limits its scope in various technical systems. This circumstance necessitates the development and application of fundamentally new methods to improve the performance, reliability and fault tolerance of CSEDPs, and in particular, methods based on the use of codes in the system of residual classes.

After the theoretical substantiation of possibility of efficiently using the SRC codes for increasing the fault tolerance of CSEDP has been carried out we move to the formulation of the optimal reservation problem in the SRC. The results of solving the problem of optimal reservation can give a general answer about the degree of efficiency of the use of SRC to improve the fault tolerance of CSEDP.

We will consider the reliability scheme of CSEDP, which is represented by a serial connection of information processing channels (IPC). To improve the reliability of CSEDP, backup information processing paths (IPP) are introduced into the respective IPCs [1].

In the design and operation of real-time CSEDPs, there is a necessity not only to ensure the required reliability by redundancy, but also to produce it as cheap as possible. At the same time, for CSEDP, it is necessary to take into account limitations in size, weight, consumed electricity, cost and other characteristics. In other words, an optimal reservation problem arises.

For the convenience of taking these restrictions into account, in the general case we will consider only one limiting factor, regardless of what it is - cost, weight, overall dimensions, etc. We will call it simply "cost".

With such a formulation of the question the following two main tasks can be solved.

Ensure the specified probability of system uptime at the minimum cost of reserve elements.

Mathematically, this problem can be formulated as follows: find the minimum of a function, provided:

$$
\left\{\begin{array}{c}
W_{c}=\sum_{i=1}^{n}\left(\omega_{i} m_{i}+\omega_{i}^{0}\right) \\
P_{c}(t)=\prod_{i=1}^{n} P_{i}\left(t, m_{i}\right) \geq P_{r s}(t),
\end{array}\right.
$$


Conceptual Principles of Providing the Information Security of the National Economy of Ukraine in the Conditions of Digitalization

where $P_{c}(t)$-system uptime probability; ${ }_{r s}(t)$ - the required value of the system uptime probability; ${ }^{W_{c}}$-system cost; ${ }^{m_{i}}$ - number of reserve elements on the i-th part of the system; $n$ - number of different parts of the system; ${ }^{\omega_{i}}$ - cost of one element of the i-th part of the system; $\omega_{i}^{0}$ - initial cost of the main element of the i-th part of the system; $P_{i}\left(t, m_{i}\right)$ - the probability of failure-free operation of the ${ }^{m_{i}}$-th part of the system if there are ${ }^{m_{i}}$ backup elements on it [9].

Ensure the highest possible probability of system failure-free operation at a given cost of backup elements.

Mathematically, this task can be formulated as follows: find the maximum of the function, provided:

$$
\left\{\begin{array}{l}
P_{c}(t)=\prod_{i=1}^{n} P_{i}\left(t, m_{i}\right) \rightarrow \max \\
W_{c}=\sum_{i=1}^{n}\left(\omega_{i} m_{i}+\omega_{i}^{0}\right) \leq W_{r s},
\end{array}\right.
$$

where $W_{r s}$ - required system cost.

To solve these problems, it is convenient to use the method of coordinatewise steepest descent. This method is the next multi-step process [10].

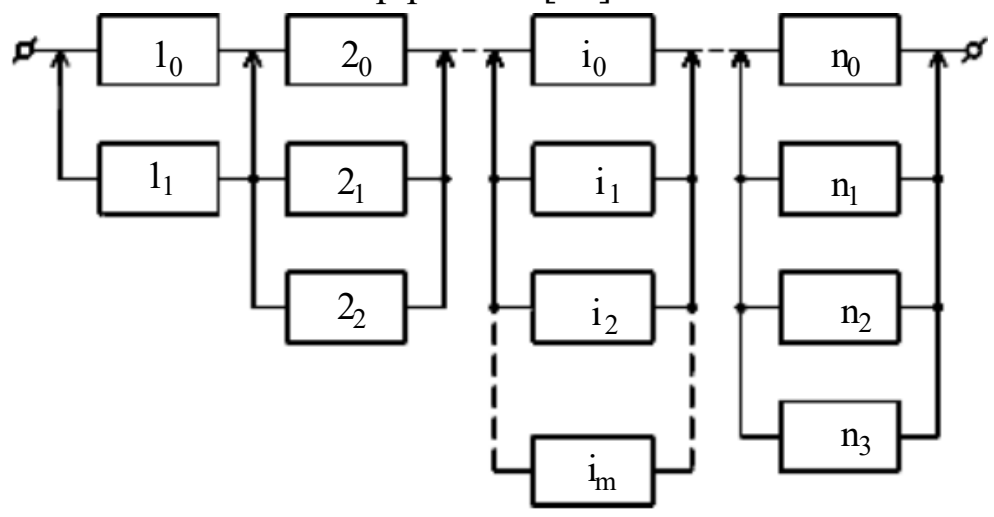

Figure 1 Reliability scheme of CSEDP

First, the source system is considered (Fig. 1), in which there is not a single backup element at each section. In this case, in each section, in general, various backup methods with different operation modes of the backup elements are allowed. At the first step, such a part of the system is found, adding one reserve element to which gives the greatest gain in the increment of the probability of the system's performance per unit cost.

In the second step, the next sector in the system is found (including the one on which the reservation was made), which is characterized by the greatest increase in the probability of failure-free system operation when the next one backup element is added. This new sector may be the one in which the reservation was made at the first step [9].

Similarly, the process continues further. Let $M$ steps of the described process be done. In this case, each $i$-th section of the system will be reserved $m_{i}$ times: 


$$
M=\sum_{i=1}^{n} m_{i} .
$$

The value of the probability of system failure-free operation at the $M$-th process step will be determined as follows:

$$
P_{c}^{M}(t)=R\left(t, m_{1}, m_{2}, \ldots, m_{i}, \ldots, m_{n}\right)=\prod_{i=1}^{n} P_{i}\left(t, m_{i}\right),
$$

where $m_{i}-$ the redundancy ratio of the $i$-th element (sector) of the system.

Similarly for step $M+1$ :

$$
P_{c}^{M+1}(t)=P\left(t, m_{1}, m_{2}, \ldots, m_{i}+1, \ldots, m_{n}\right) .
$$

By the condition of the problem, the effectiveness of each step is evaluated by the ratio

$$
\gamma_{i}\left(m_{i}+1\right)=\frac{P_{c}^{M+1}(t)-P_{c}^{M}(t)}{\omega_{i}},
$$

where $\omega_{l}-$ cost of $i$-th element that was added to the system at the $(M+1)$-th step.

Substituting the values, we obtain:

$$
\begin{aligned}
& \gamma_{i}\left(m_{i}+1\right)=\frac{1}{\omega_{i}}\left[P\left(t, m_{1}, m_{2}, \ldots, m_{i}+1, \ldots, m_{n}\right)-P\left(t, m_{1}, m_{2}, \ldots, m_{i}, \ldots, m_{n}\right)\right]= \\
& =\frac{1}{\omega_{i}}\left[P_{1}\left(t, m_{1}\right) P_{2}\left(t, m_{2}\right), \ldots, P_{i}\left(t, m_{i}+1\right), \ldots, P_{n}\left(t, m_{n}\right)-P_{1}\left(t, m_{1}\right) P_{2}\left(t, m_{2}\right), \ldots, P_{i}\left(t, m_{i}\right), \ldots, P_{n}\left(t, m_{n}\right)=\right. \\
& =\frac{1}{\omega_{i}}\left[P_{i}\left(t, m_{i}+1\right) \prod_{\substack{k=1 \\
k \neq i}}^{n} P_{k}\left(t, m_{k}\right)-\prod_{k=1}^{n} P_{k}\left(t, m_{k}\right)\right]=\frac{1}{\omega_{i}} P_{k}\left(t, m_{k}\right)\left[\frac{P_{i}\left(t, m_{i}+1\right)}{P_{i}\left(t, m_{i}\right)}-1\right]= \\
& =P_{c}^{M}(t) \frac{P_{i}\left(t, m_{i}+1\right)-P_{i}\left(t, m_{i}\right)}{\omega_{i} P_{i}\left(t, m_{i}\right)} .
\end{aligned}
$$

The value $P_{c}^{M}(t)$ enters expression (7) for all values $i=1,2, \ldots, n$. In the general case, at each step of the process, only the relative value $\tilde{\gamma}\left(m_{i}+1\right)$ is of interest as compared to other similar relative values. From this follows that the process will not change if at each step you choose the area with the largest:

$$
\gamma_{i}\left(m_{i}+1\right)=\frac{P_{i}\left(t, m_{i}+1\right)-P_{i}\left(t, m_{i}\right)}{\omega_{i} P_{i}\left(t, m_{i}\right)} .
$$

Thus, having calculated the values $\gamma_{i}\left(m_{i}+1\right)$ for each section of the system, one can determine in which sequence the reserve elements should be added so that, stopping at the necessary process step, one can satisfy the conditions of the first or second task [11].

In the general case, the method of calculating the optimal reservation, in which the coordinatewise steepest descent method is used, consists of the following main steps [12].

The system (Fig. 1), consisting of $n$ sections is considered. The system is considered (Fig. 1), consisting of sections. First of all, it is necessary for each i-th segment to determine, at various backup multiplicities $m_{i}$ the probability values of fault-free operation $P_{i}\left(t, m_{i}\right)$ for a certain fixed time interval with a corresponding backup method, which is possible for this system section, according to one of the known reliability theory formulas [13]. 
Conceptual Principles of Providing the Information Security of the National Economy of Ukraine in the Conditions of Digitalization

A summary table 1 of $P_{i}\left(t, m_{i}\right)$ values is compiled for all practically possible $m_{i}$ and different $i=1,2, \ldots, n$ (for different parts of the system), obtained by the specified formulas.

Table 1 Summary table of variable values

\begin{tabular}{|c|c|c|c|c|c|c|}
\hline$m_{i}$ & $P_{1}(t)$ & $P_{2}(t)$ & $\ldots$ & $P_{i}(t)$ & $\ldots$ & $P_{n}(t)$ \\
\hline 0 & $P_{1}(t, 0)$ & $P_{2}(t, 0)$ & $\ldots$ & $P_{i}(t, 0)$ & $\ldots$ & $P_{n}(t, 0)$ \\
\hline 1 & $P_{1}(t, 1)$ & $P_{2}(t, 1)$ & $\ldots$ & $P_{i}(t, 1)$ & $\ldots$ & $P_{n}(t, 1)$ \\
\hline 2 & $P_{1}(t, 2)$ & $P_{2}(t, 2)$ & $\ldots$ & $P_{i}(t, 2)$ & $\ldots$ & $P_{n}(t, 2)$ \\
\hline$\ldots$ & $\ldots$ & $\ldots$ & $\ldots$ & $\ldots$ & $\ldots$ & $\ldots$ \\
\hline$m_{i}$ & $P_{1}(t, m)$ & $P_{2}(t, m)$ & $\ldots$ & $P_{i}(t, m)$ & $\ldots$ & $P_{n}(t, m)$ \\
\hline$\ldots$ & $\ldots$ & $\ldots$ & $\ldots$ & $\ldots$ & $\ldots$ & $\ldots$ \\
\hline
\end{tabular}

Based on the obtained values $P_{i}\left(t, m_{i}\right)$, summarized in table 1 , and the known values of the cost of the elements $\omega_{i}, \gamma_{i}\left(m_{i}\right)$ is calculated by the formula (8) for all values of $i$ and different values of $m_{i}$, after which the table 2 is compiled.

All values $\gamma_{i}\left(m_{i}\right)$ in table 2 are renumbered in each of the columns in descending order, and then we number all the values $\gamma^{\prime}(k)$ in descending order, and the next multi-step process is investigated.

Table 2 Summary table of the obtained data

\begin{tabular}{|c|c|c|c|c|c|c|}
\hline$m_{i}$ & $\gamma_{1}$ & $\gamma_{2}$ & $\ldots$ & $\gamma_{i}$ & $\ldots$ & $\gamma_{n}$ \\
\hline 0 & - & - & $\ldots$ & - & $\ldots$ & - \\
\hline 1 & $\gamma_{1}(1)$ & $\gamma_{2}(1)$ & $\ldots$ & $\gamma_{i}(1)$ & $\ldots$ & $\gamma_{n}(1)$ \\
\hline 2 & $\gamma_{1}(2)$ & $\gamma_{2}(2)$ & $\ldots$ & $\gamma_{i}(2)$ & $\ldots$ & $\gamma_{n}(2)$ \\
\hline$\ldots$ & $\ldots$ & $\ldots$ & $\ldots$ & $\ldots$ & $\ldots$ & $\ldots$ \\
\hline$m_{i}$ & $\gamma_{1}(m)$ & $\gamma_{2}(m)$ & $\ldots$ & $\gamma_{i}(m)$ & $\ldots$ & $\gamma_{n}(m)$ \\
\hline
\end{tabular}

In the first step: $\gamma$ is selected with the number 1 (the maximum of the values $\gamma_{i}(1)$ ); on the table. 1 the corresponding value is sought; value is calculated:

$$
P_{c}^{(1)}(t)=\frac{P_{i}(t, 1)}{P_{i}(t, 0)} P_{c}^{(0)}(t),
$$

where $P_{c}^{(0)}(t)=\prod_{k=1}^{n} P_{k}(t, 0)$ - the initial value of the probability of failure of the source system (without reservation); value is calculated:

$$
W_{c}^{(1)}=W_{c}^{(0)}+\omega_{i}
$$

where $W_{c}^{(0)}$ - initial cost of the system;

$\omega_{i}$ - the cost of one element that is intended for reservation of the $i$-th segment. 
At the second step: $\gamma$ is selected with the number 2 (the maximum among remaining $\gamma_{k}(1)$ for $k \neq 1$ or $\left.\gamma_{i}(2)\right)$; on the table 1 the corresponding value $P_{k}(t, 1)$ is sought (or $P_{i}(t, 2)$, if number 2 has $\left.\gamma_{i}(2)\right)$; value is calculated:

$$
\begin{aligned}
& P_{c}^{(2)}(t)=\frac{P_{k}(t, 1)}{P_{k}(t, 0)} P_{c}^{(1)}(t), \\
& P_{c}^{(2)}(t)=\frac{P_{i}(t, 2)}{P_{i}(t, 1)} P_{c}^{(1)}(t),
\end{aligned}
$$

or

if number 2 has $\gamma_{i}(2)$, value is calculated:

$$
\begin{aligned}
& W_{c}^{(2)}=W_{c}^{(1)}+\omega_{k}, \\
& W_{c}^{(2)}=W_{c}^{(1)}+\omega_{i},
\end{aligned}
$$

or

if number 2 has $\gamma_{i}(2)$.

Then this multi-step process continues with the use of expressions:

$$
\begin{aligned}
& P_{c}^{M}(t)=\frac{P_{i}\left(t, m_{i}\right)}{P_{i}\left(t, m_{i}-1\right)} P^{M-1}, \\
& W_{c}^{(M)}=W_{c}^{(M-1)}+\omega_{i},
\end{aligned}
$$

while $m_{i} \geq 0, M \geq 0$.

The process stops at step:

$$
M\left(M=\sum_{i=1}^{n} m_{i}\right),
$$

when the condition is met for the first task:

$$
P_{c}^{(M-1)}(t)<P_{r s}(t) \leq P_{c}^{M}(t),
$$

and for the second task the following condition is met:

$$
W_{c}^{M} \leq W_{r s} \leq W_{c}^{(M+1)} .
$$

From tab. 4 it can be seen that no matter what problem is solved, what is the solution process, and the conditions for choosing $\gamma_{i}$ - at each step the minimum "cost" of the system is automatically ensured.

The reliability scheme of CSEDP in SRC is presented in fig. 2, where $Y R_{i}$ is the reservation sector corresponding to $\mathrm{IPC}_{m_{i}}$ modulo $m_{i}$ of SRC. As a result of solving the problem of optimal redundancy in the SRC, it is necessary to obtain the numerical values $x_{i}$ of the coordinates of the state vector $X_{S R C}^{(l)}=\left\{x_{i}\left\|x_{2}\right\| \ldots\left\|x_{i}\right\| \ldots \| x_{n}\right\}$ of the reserved CSEDP in SRC, where: $x_{i}$ - total number of $\mathrm{IPP}_{i}(\mathrm{IPP})$ in $\mathrm{IPC}_{m_{i}}$ modulo $m_{i}$ of SRC; $n$ - number of bases in SRC [9]. 
Conceptual Principles of Providing the Information Security of the National Economy of Ukraine in the Conditions of Digitalization

Table 3 Set of intermediate values

\begin{tabular}{|c|c|c|c|c|c|c|}
\hline$M$ & $m_{1}$ & $m_{2}$ & $\ldots$ & $m_{n}$ & $P_{i}^{(M)}(t)$ & $W_{c}^{(M)}$ \\
\hline 0 & 0 & 0 & $\ldots$ & 0 & $P_{i}^{(0)}(t)$ & $W_{c}^{(0)}$ \\
\hline$\ldots$ & $\ldots$ & $\ldots$ & $\ldots$ & $\ldots$ & $\ldots$ & $\ldots$ \\
\hline 1 & 1 & 0 & $\ldots$ & 0 & $P_{i}^{(1)}(t)$ & $W_{c}^{(1)}$ \\
\hline 5 & 1 & 3 & $\ldots$ & 0 & $P_{i}^{(5)}(t)$ & $W_{c}^{(5)}$ \\
\hline 6 & 2 & 3 & $\ldots$ & 1 & $P_{i}^{(6)}(t)$ & $W_{c}^{(6)}$ \\
\hline$\ldots$ & $\ldots$ & $\ldots$ & $\ldots$ & 1 & $\ldots$ & $\ldots$ \\
\hline
\end{tabular}

Table 4 Table of solutions for the optimal reservation problem

\begin{tabular}{|c|c|c|}
\hline$M$ & $P_{i}^{(M)}(t)$ & $W_{c}^{(M)}$ \\
\hline 0 & $P_{i}^{(0)}(t)$ & $W_{c}^{(9)}$ \\
\hline 1 & $P_{i}^{(1)}(t)$ & $W_{c}^{(1)}$ \\
\hline 2 & $P_{i}^{(2)}(t)$ & $W_{c}^{(2)}$ \\
\hline$\ldots$ & $\ldots$ & $\ldots$ \\
\hline
\end{tabular}

General source data for solving the problem of optimal reservation in SRC are given in table 5. This table shows the totality of the optimal bases of SRC for $l$-byte bit grids of CSEDP [1].

Table 5 Set of optimal bases of SRC

\begin{tabular}{|c|c|c|c|c|c|c|c|c|c|c|c|c|c|c|c|c|}
\hline \multirow{3}{*}{$l$} & \multicolumn{16}{|c|}{ SRC bases } \\
\hline & $m_{1}$ & $m_{2}$ & $m_{3}$ & $m_{4}$ & $m_{5}$ & $m_{6}$ & $m_{7}$ & $m_{8}$ & $m_{9}$ & $m_{10}$ & $m_{11}$ & $m_{12}$ & $m_{13}$ & $m_{14}$ & $m_{15}$ & $m_{16}$ \\
\hline & $\alpha_{1}$ & $\alpha_{2}$ & $\alpha_{3}$ & $\alpha_{4}$ & $\alpha_{5}$ & $\alpha_{6}$ & $\alpha_{7}$ & $\alpha_{8}$ & $\alpha_{9}$ & $\alpha_{10}$ & $\alpha_{11}$ & $\alpha_{12}$ & $\alpha_{12}$ & $\alpha_{14}$ & $\alpha_{15}$ & $\alpha_{16}$ \\
\hline \multirow[t]{2}{*}{1} & 3 & 4 & 5 & 7 & - & - & - & - & - & - & - & - & - & - & - & - \\
\hline & 2 & 2 & 3 & 3 & - & - & - & - & - & - & - & - & - & - & - & - \\
\hline \multirow[t]{2}{*}{2} & 2 & 5 & 7 & 9 & 11 & 13 & - & - & - & - & - & - & - & - & - & - \\
\hline & 1 & 3 & 3 & 4 & 4 & 4 & - & - & - & - & - & - & - & - & - & - \\
\hline \multirow[t]{2}{*}{3} & 3 & 4 & 5 & 11 & 13 & 17 & 19 & - & - & - & - & - & - & - & - & - \\
\hline & 2 & 2 & 3 & 4 & 4 & 5 & 5 & - & - & - & - & - & - & - & - & - \\
\hline \multirow[t]{2}{*}{4} & 2 & 3 & 5 & 7 & 11 & 13 & 17 & 19 & 23 & 29 & - & - & - & - & - & - \\
\hline & 1 & 2 & 3 & 3 & 4 & 4 & 5 & 5 & 5 & 5 & - & - & - & - & - & - \\
\hline \multirow[t]{2}{*}{8} & 2 & 3 & 5 & 7 & 11 & 13 & 17 & 19 & 23 & 29 & 31 & 37 & 41 & 43 & 47 & 53 \\
\hline & 1 & 2 & 3 & 3 & 4 & 4 & 5 & 5 & 5 & 5 & 5 & 6 & 6 & 6 & 6 & 6 \\
\hline
\end{tabular}

In accordance with the main stages of solving the optimization problem, consider a specific practical example for $l=1$. In this case (see table 5), the set of bases for the SRC is determined by the following set of modules $m_{1}=3, m_{2}=4, m_{3}=5$ and $m_{4}=7$ (respectively $\alpha_{1}=\alpha_{2}=2$ and $\left.\alpha_{3}=\alpha_{4}=3\right) ; V_{\text {set }}^{(l)}=24 ; P_{\text {set }}\left(t_{\text {set }}=1\right.$ hour $)=0,9999$; probability of failure-free operation of one $\mathrm{IPP}_{m_{i}}$ of $\mathrm{IPC}_{i}$ of CSEDP in $t_{\text {set }}=1$ hour equals to $P_{i}(t)=e^{-\lambda_{i} t}=e^{-\alpha_{i} \lambda_{r} t}$, where $\lambda_{r}-$ failure rate of CSEDP equipment, per unit of the bit grid. In this case, when solving problems of optimal reservation, we will use the recommended method of coordinatewise steepest descent. The solution of the problem of optimal redundancy by coordinatewise steepest descent 
is based on finding the extremum of a certain function by successive steps from the initial point of the solution along the gradient direction or in some cases along one of the directions having the maximum partial derivative [9].

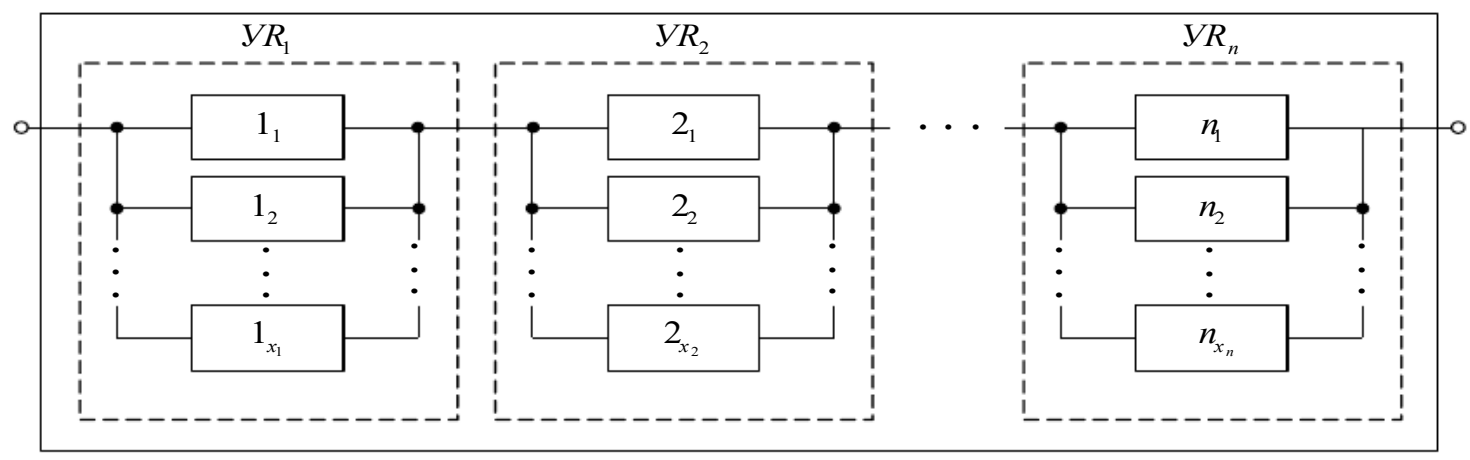

Figure 2 Reliability scheme of CSEDP in SRC

The very process of the synthesis of the optimal reservation of CSEDP in SRC can be represented as an iterative process. At the beginning of the task solving process, the initial reliability structure of CSEDP in the SRC is analyzed (Fig. 2). At the first step, the $Y R$ of the system is found, which adding one IPP gives the greatest gain in the increase in the probability of failure-free operation of CSEDP $P(t)$. At the second step, the next $Y R$ is found ((including the one that already has an additional (reserve) IPP) which is characterized by the greatest increase in $P(t)$ when adding this IPP. Similarly, the process continues further.

The method of solving the problem of optimal reservation using the method of coordinatewise steepest descent is described. In this case, the following table 6 where $P_{i}^{(K)}(t)=1-\left[1-P_{i}^{(0)}(t)\right]^{K+1}$, where $P_{i}^{(0)}(t)$ - probability of failure-free operation of $\mathrm{IPC}_{m_{i}}$ modulo $m_{i}$ of SRC, consisting of one $\operatorname{IPP}_{i} ; P_{i}^{(K)}(t)$ - probability of failure-free operation $\mathrm{IPC}_{m_{i}}$ with application of $K$-fold reservation of $\operatorname{IPP}_{i}$, a $P_{\Sigma}^{(K)}(t)=\prod_{i=1}^{n} P_{i}^{(K)}(t)$ - probability of failure-free operation of CSEDP in SRC with simultaneous $K$-fold reservation in each of $n$ of $\mathrm{IPC}_{m_{i}}, K=\overline{0,4}$.

The obtained data is summarized in table 6 .

Table 6 Calculated values of reliability of CSEDP

\begin{tabular}{|c|c|c|c|c|c|}
\hline Reservation ratio $K$ & $\begin{array}{c}P_{1}^{(K)}(t) \\
\left(m_{1}\right)\end{array}$ & $\begin{array}{c}P_{2}^{(K)}(t) \\
\left(m_{2}\right)\end{array}$ & $\begin{array}{c}P_{3}^{(K)}(t) \\
\left(m_{3}\right)\end{array}$ & $\begin{array}{c}P_{4}^{(K)}(t) \\
\left(m_{4}\right)\end{array}$ & $P_{\Sigma}^{(K)}(t)$ \\
\hline 0 & $P_{1}^{(0)}(t)$ & $P_{2}^{(0)}(t)$ & $P_{3}^{(0)}(t)$ & $P_{4}^{(0)}(t)$ & $P_{\Sigma}^{(0)}(t)$ \\
\hline 1 & $P_{1}^{(1)}(t)$ & $P_{2}^{(1)}(t)$ & $P_{3}^{(1)}(t)$ & $P_{4}^{(1)}(t)$ & $P_{\Sigma}^{(1)}(t)$ \\
\hline 2 & $P_{1}^{(2)}(t)$ & $P_{2}^{(2)}(t)$ & $P_{3}^{(2)}(t)$ & $P_{4}^{(2)}(t)$ & $P_{\Sigma}^{(2)}(t)$ \\
\hline
\end{tabular}


Conceptual Principles of Providing the Information Security of the National Economy of Ukraine in the Conditions of Digitalization

$P_{4}^{(0)}(t)=e^{-\lambda_{4} t}=e^{-\alpha_{4} \cdot \lambda_{r} \cdot t}=e^{-3 \cdot \lambda_{r} \cdot t}$ and $P_{\Sigma}^{(0)}(t)$ is equal to:

$P_{\Sigma}^{(0)}(t)=\prod_{i=1}^{4} P_{i}^{(0)}(t)=P_{1}^{(0)}(t) \cdot P_{2}^{(0)}(t) \cdot P_{3}^{(0)}(t) \cdot P_{4}^{(0)}(t)=e^{-2 \cdot \lambda_{r} \cdot t} \cdot e^{-2 \cdot \lambda_{r} \cdot t} \cdot e^{-3 \cdot \lambda_{r} \cdot t} \cdot e^{-3 \cdot \lambda_{r} \cdot t}=e^{-10 \cdot \lambda_{r} \cdot t}$

The results of calculations of the probability of failure-free operation for the values $l=1$, $\lambda_{r}=10^{-4}[1 /$ hour $]$ and $t_{\text {set }}=1$ [hour] are placed in the table 7 .

Table 7 Estimated values of the probability of failure-free operation for $l=1$

\begin{tabular}{|c|c|c|c|c|c|}
\hline \multirow{2}{*}{ Ratio } & \multicolumn{4}{|c|}{$P_{i}^{(K)}(t)$} & \multirow{2}{*}{$P_{\Sigma}^{(K)}(t)$} \\
\cline { 2 - 6 } & $m_{1}=3$ & $m_{2}=4$ & $m_{3}=5$ & $m_{4}=7$ & \\
\hline 0 & 0,999800019998667 & 0,999800019998667 & 0,9997000444995500 & 0,999700044995500 & 0,999000499833375 \\
\hline 1 & 0,999999960007999 & 0,9999999960007999 & 0,999999910026995 & 0,9999999910026995 & 0,9999999740070013 \\
\hline 2 & 0,999999999992002 & 0,999999999992002 & 0,999999999973012 & 0,9999999999973012 & 0,999999999930029 \\
\hline 3 & 0,999999999999998 & 0,999999999999998 & 0,9999999999999992 & 0,9999999999999992 & 0,9999999999999981 \\
\hline 4 & 1,000000000000000 & 1,000000000000000 & 1,000000000000000 & 1,000000000000000 & 1,000000000000000 \\
\hline 5 & 1,000000000000000 & 1,000000000000000 & 1,000000000000000 & 1,000000000000000 & 1,000000000000000 \\
\hline
\end{tabular}

Based on the results of the calculations placed in the table 7 and in accordance with the optimization algorithm, as well as taking into account the "cost" $\alpha_{1} \operatorname{IPP}_{i}$ we will calculate the values $Z_{i}^{(j)}$ (table 8$)$.

$$
Z_{i}^{(j)}=\frac{P_{i}^{(j)}(t)-P_{i}^{(j-1)}(t)}{\alpha_{i} \cdot P_{i}^{(j-1)}(t)}
$$

for $i=\overline{1, n}$ and $j=\overline{1, k}$.

In our case $(l=1)$ we have: $i=\overline{1,4} ; j=\overline{1,4} ; \alpha_{1}=\alpha_{2}=2$ and $\alpha_{3}=\alpha_{4}=3$. The results of the calculations for $l=1$ are placed in the table 9 .

Table 8 Calculated data of values of $Z_{i}^{(j)}$

\begin{tabular}{|c|c|c|c|c|}
\hline Reservation ratio $K$ & $Z_{1}^{(j)}$ & $Z_{2}^{(j)}$ & $Z_{3}^{(j)}$ & $Z_{4}^{(j)}$ \\
\hline 0 & - & - & - & - \\
\hline 1 & $Z_{1}^{(1)}$ & $Z_{2}^{(1)}$ & $Z_{3}^{(1)}$ & $Z_{4}^{(1)}$ \\
\hline 2 & $Z_{1}^{(2)}$ & $Z_{2}^{(2)}$ & $Z_{3}^{(2)}$ & $Z_{4}^{(2)}$ \\
\hline
\end{tabular}

Table 9 Calculated data of values of $Z_{i}^{(j)}$ for $l=1$

\begin{tabular}{|c|c|c|c|c|c|c|c|c|}
\hline \multirow[b]{2}{*}{$K$} & \multicolumn{8}{|c|}{ SRC bases for $l=1$} \\
\hline & $m_{1}=3$ & & $m_{2}=4$ & & $m_{3}=5$ & & $m_{4}=7$ & \\
\hline 0 & - & & - & & - & & - & \\
\hline 1 & 0,0000999900006666 & & 0,0000999900006666 & || 1 & 0,0000999850014999 & & 0,0000999850014999 & 2 \\
\hline 2 & 0,0000000199920025 & 4 & 0,0000000199920025 & $\| 4$ & 0,0000000299820083 & & 0,0000000299820083 & 3 \\
\hline 3 & 0,0000000000039980 & 6 & 0,0000000000039980 & $\| 6$ & 0,0000000000089933 & & 0,0000000000089933 & 5 \\
\hline 4 & 0,0000000000000008 & 8 & 0,0000000000000008 & $\| 8$ & 0,0000000000000027 & & 0,0000000000000027 & 7 \\
\hline 5 & 0,0000000000000000 & $\mid 99$ & 0,0000000000000000 & || 9 & 0,0000000000000000 & & 0,0000000000000000 & 9 \\
\hline
\end{tabular}


Further analysis of the contents of the table 8 in terms of the values of the contents of this table. We number all values $Z_{i}^{(j)}$ in descending order, i.e. create a table with values $Z_{i N}^{(j)} \|(N)$, where $N=1,2,3, \ldots$. While $Z_{i 1}^{(j)}>Z_{i 2}^{(j)}>Z_{3}^{(j)}>\ldots$. After that, a multi-stage optimization process is carried out [9].

First stage. We take the maximum value of $Z_{i 1}^{(j)} \|(1)$ from table 9 . By the value $i$ of the expression $Z_{i 1}^{(j)}(i$ - column number of the table 7 ) and by the value $K=1$ (row number) of the table 7, on the corresponding coordinates $\left(m_{i}, K=1\right)$, we select the desired value of $P_{i}^{(1)}(t)$ . Then the value $P_{S R C}^{(1)}(t)=\frac{P_{i}^{(1)}(t)}{P_{i}^{(0)}(t)} \cdot P_{\Sigma}^{(0)}(t)$ is determined, where $P_{\Sigma}^{(0)}(t)=\prod_{i=1}^{n} P_{i}^{(0)}(t)$ (see table 7), as well as the value of "cost" of CSEDP $V_{S R C}^{(1)}=\sum_{i=1}^{n} \alpha_{i}$. Values of $P_{S R C}^{(1)}(t)$ and $V_{S R C}^{(1)}$ are recorded in the final decision table (table 10).

Second stage. From table 10 we choose the value of $Z_{i 2}^{(j)} \|(2)$, according to which to the table $6(K=1, K=2, K=3$ and $K=4)$ select the appropriate value $P_{i}^{(2)}(t)$ or $P_{\rho \nexists i}^{(1)}(t)$. Then determine the value:

$$
P_{S R C}^{(2)}(t)=\frac{P_{\rho}^{(1)}(t)}{P_{\rho}^{(0)}(t)} \cdot P_{S R C}^{(1)}(t) \text { or } P_{S R C}^{(2)}(t)=\frac{P_{i}^{(2)}(t)}{P_{i}^{(1)}(t)} \cdot P_{S R C}^{(1)}(t) .
$$

We calculate the value of "cost" $V_{S R C}^{(2)}$. The obtained values are recorded in the final table 10.

Next, this multi-step process continues when using:

$$
P_{S R C}^{(M)}(t)=\frac{P_{i}^{(M)}(t)}{P_{i}^{(M-1)}(t)} \cdot P_{S R C}^{(M-1)}(t) .
$$

All obtained data is summarized in the final table 10.

The calculation process stops at step $M=\sum_{i=1}^{n} m_{i}$, or when the condition for the direct optimal reservation problem $P_{S R C}^{(M-1)}(t)<P_{\text {required }}(t)<P_{S R C}^{(M)}(t)$ is met or when the condition for the inverse problem of optimal reservation $V_{S R C}^{(M)} \leq V_{\text {set }}^{(l)}<V_{S R C}^{(M+1)}$ is met.

\begin{tabular}{|c|c|c|c|c|c|c|}
\hline \multirow{2}{*}{$K$} & \multicolumn{4}{|c|}{$P_{i}^{(K)}(t)$} & \multirow{2}{*}{$P_{\Sigma}^{(K)}(t)$} & \multirow{2}{*}{$V_{S R C}^{(l)}$} \\
\hline & $m_{1}$ & $m_{2}$ & $m_{3}$ & $m_{4}$ & & \\
\hline 0 & $\begin{array}{c}0,9998000199986 \\
67\end{array}$ & $\begin{array}{c}0,9998000199986 \\
67\end{array}$ & $\begin{array}{c}0,9997000449955 \\
00\end{array}$ & $\begin{array}{c}0,9997000449955 \\
00\end{array}$ & $\begin{array}{c}0,999000499833 \\
375\end{array}$ & 10 \\
\hline 1 & $\begin{array}{c}0,9999999600079 \\
99 \|_{1}\end{array}$ & $\begin{array}{c}0,9998000199986 \\
67\end{array}$ & $\begin{array}{c}0,9997000449955 \\
00\end{array}$ & $\begin{array}{c}0,9997000449955 \\
00\end{array}$ & $\begin{array}{c}0,999200279954 \\
664\end{array}$ & 12 \\
\hline 2 & $\begin{array}{c}0,9999999600079 \\
99\end{array}$ & $\begin{array}{c}0,9999999600079 \\
99|| 2\end{array}$ & $\begin{array}{c}0,9997000449955 \\
00\end{array}$ & $\begin{array}{c}0,9997000449955 \\
00\end{array}$ & $\begin{array}{c}0,999400100027 \\
981\end{array}$ & 14 \\
\hline 3 & $\begin{array}{c}0,9999999600079 \\
99 \\
\end{array}$ & $\begin{array}{c}0,9999999600079 \\
99\end{array}$ & $\begin{array}{c}0,9999999100269 \\
95 \| 3\end{array}$ & $\begin{array}{c}0,9997000449955 \\
00\end{array}$ & $\begin{array}{c}0,999699875089 \\
482\end{array}$ & 17 \\
\hline
\end{tabular}

Table 10 Table of solutions for the optimal reservation problem 
Conceptual Principles of Providing the Information Security of the National Economy of Ukraine in the Conditions of Digitalization

\begin{tabular}{|c|c|c|c|c|c|c|}
\hline \multirow{2}{*}{4} & 0,9999999600079 & 0,9999999600079 & 0,9999999100269 & 0,9999999100269 & 0,999999740070 & 2 \\
& 99 & 99 & 95 & $95 \| 4$ & 013 & 20 \\
\hline \multirow{2}{*}{5} & 0,9999999600079 & 0,9999999600079 & 0,9999999999730 & 0,9999999100269 & 0,999999830016 & 2 \\
& 99 & 99 & $12 \| 5$ & 95 & 014 & 23 \\
\hline \multirow{2}{*}{6} & $\begin{array}{c}0,9999999600079 \\
09\end{array}$ & 0,9999999600079 & 0,9999999999730 & 0,99999999999730 & 0,999999919962 & 26 \\
& 99 & 12 & $12 \| 6$ & 024 & 26 \\
\hline
\end{tabular}

Analysis of the values of the final table 10 shows that no matter what problem is solved this method ensures the minimum "cost" (the minimum amount of equipment $V_{S R C}^{(l)}=\min$ ) of CSEDP when solving the direct problem of optimal reservation in SRC, and the maximum possible value of the probability of failure-free operation $P_{S R C}^{(l)}(t)$ while solving the inverse problem of optimal reservation in the SRC [14].

\section{RESULTS OF STUDY}

Based on the results of the solution of the optimal reservation problem in SRC, you can get the desired state vector of CSEDP in SRC. In this case, the IPC modulo $m_{i}$ contains $x_{i}$ IPP (one main and $x_{i}-1$ reserve).

$$
X_{S R C}^{(l)}=\left\{x_{1}\left\|x_{2}\right\| \ldots\left\|x_{i}\right\| \ldots \| x_{n}\right\} .
$$

The number of CSEDP equipment in SRC is $V_{S R C}^{(l)}=\sum_{i=1}^{n} x_{i} \cdot \alpha_{i}$.

Based on the structure of the state vector $X$ it is easy to obtain a mathematical model of the reliability of CSEDP in SRC for a given value $t_{\text {set }}$. So, for the state vector (21) in general, the mathematical model of the reliability of CSEDP in SRC will be as follows:

$$
P_{S R C}^{(l)}(t)=\left\{1-\left[1-P_{1}^{(0)}(t)\right]^{x_{1}+1}\right\} \cdot\left\{1-\left[1-P_{2}^{(0)}(t)\right]^{x_{2}+1}\right\} \cdot \ldots \cdot\left\{1-\left[1-P_{n}^{(0)}(t)\right]^{x_{n}+1}\right\} .
$$

For SRC with $n=4 l=1$ will have the form of table 10, and the final table has the form of table 12. Based on the contents of the table 16 we compose the reliability structures of CSEDP in SRC (see table 11).

If it is necessary to provide a given level of reliability of CSEDP in SRC $P_{\text {set }}(t)=0,9999$ with a minimum amount of equipment $V_{S R C}$ (the direct problem of optimal reservation) for $l=1$, then according to table 10 (row - reservation ratio $K=4$ ) we determine that for a given level $P_{\text {set }}(t)$ of reliability we have $P_{\Sigma}^{(K)}(t)=0,9999997>P_{\text {set }}(t)=0,9999$, that is ensured when $V_{S R C}^{(l)}=20$. At the same time, the optimal reliability structure of CSEDP in the SRC is determined by the structure with number 5 of table 11 .

The maximum value of the probability of failure-free operation $P_{\Sigma}^{(K)}(t)$ of CSEDP in SRC under a given restriction on the number of equipment $V_{\text {set }}^{(l)}=24$ (the inverse problem of optimal reservation) will be $P_{\Sigma}^{(K)}(t)=0,99999999997$ (Table 10, $K=5$ ), while $V_{S R C}^{(l)}=23$. The optimal reliability structure of CSEDP in SRC for the above initial data is defined as number 6 in the table 11. On the basis of this reliability structure, the structure of CSEDP in SRC is synthesized, which is shown in Fig. 2.5. 
Svitlana Onyshchenko, Alina Yanko, Alina Hlushko and Svitlana Sivitska

Table 11 Reliability structures of CSEDP in SRC for $l=1$

\begin{tabular}{|c|c|c|c|c|c|c|}
\hline \multirow{2}{*}{$\begin{array}{l}\text { The } \\
\text { redundancy } \\
\text { ratio }\end{array}$} & \multirow{2}{*}{$\begin{array}{c}\text { Structure } \\
\text { number }\end{array}$} & \multicolumn{4}{|c|}{ Structure nümber } & \multirow{2}{*}{$\mathrm{V}_{\mathrm{SRC}}^{(1)}$} \\
\hline & & $\mathrm{m}_{1}=3$ & $\mathrm{~m}_{2}=4$ & $\mathrm{~m}_{3}=5$ & $\mathrm{~m}_{4}=7$ & \\
\hline 0 & 1 & & & & & 10 \\
\hline 1 & 2 & & & & & 12 \\
\hline 2 & 3 & & & & & 14 \\
\hline 3 & 4 & & & & & 17 \\
\hline 4 & 5 & & & & & 20 \\
\hline 5 & 6 & & & & & 23 \\
\hline
\end{tabular}

Using the method described above, we will solve the problem of optimal reservation for $l=1$. The results of the calculations are given in tables 12-14.

Table 12 Set of bases $\left\{m_{i}\right\}$ of SRC and the "cost" of equipment $a_{i}$ for $l=1$

\begin{tabular}{|c|l|l|l|l|}
\hline$m_{i}$ & 3 & 4 & 5 & 7 \\
\hline$a_{i}$ & 2 & 2 & 3 & 3 \\
\hline
\end{tabular}

Table 13 Probability of fault-free operation $P(t)$ for $l=1, t=1$ hour, $\lambda_{r}=10^{-4}[1 /$ hour $]$

\begin{tabular}{|c|c|c|c|c|c|}
\hline \multirow{2}{*}{ Ratio } & \multicolumn{4}{|c|}{ SRC bases } & \multirow{2}{*}{$P(t)$} \\
\hline & $m_{1}=3$ & $m_{2}=4$ & $m_{3}=5$ & $m_{4}=7$ & \\
\hline 0 & 0,999800019998667 & 0,999800019998667 & 0,999700044995500 & 0,999700044995500 & 0,999000499833375 \\
\hline 1 & 0,999999960007999 & 0,999999960007999 & 0,999999910026995 & 0,999999910026995 & 0,999999740070013 \\
\hline 2 & 0,999999999992002 & 0,9999999999992002 & 0,999999999973012 & 0,999999999973012 & 0,999999999930029 \\
\hline 3 & 0,9999999999999998 & 0,9999999999999998 & 0,9999999999999992 & 0,9999999999999992 & 0,999999999999981 \\
\hline 4 & 1,000000000000000 & 1,000000000000000 & 1,000000000000000 & 1,000000000000000 & 1,000000000000000 \\
\hline 5 & 1,000000000000000 & 1,000000000000000 & 1,000000000000000 & 1,000000000000000 & 1,000000000000000 \\
\hline
\end{tabular}


Conceptual Principles of Providing the Information Security of the National Economy of Ukraine in the Conditions of Digitalization

Table 14 Summary table of values of $P(t)$ for $l=1, t=1$ hour, $\lambda_{r}=10^{-4}[1 /$ hour $]$

\begin{tabular}{|c|c|c|c|c|c|c|}
\hline \multirow{2}{*}{ № } & \multicolumn{4}{|c|}{ SRC bases } & \multirow{2}{*}{$P(t)$} & \multirow{2}{*}{$\begin{array}{c}V \\
V_{\text {max }}=24\end{array}$} \\
\hline & $m_{1}=3$ & $m_{2}=4$ & $m_{3}=5$ & $m_{4}=7$ & & \\
\hline 0 & 0,999800019998667 & 0,999800019998667 & 0,999700044995500 & 0,999700044995500 & 0,999000499833375 & 10 \\
\hline 1 & 0,999999960007999 & 0,999800019998667 & 0,999700044995500 & 0,999700044995500 & 0,999200279954664 & 12 \\
\hline 2 & 0,999999960007999 & 0,999999960007999 & 0,999700044995500 & 0,999700044995500 & 0,999400100027981 & 14 \\
\hline 3 & 0,999999960007999 & 0,999999960007999 & 0,999999910026995 & 0,999700044995500 & 0,999699875089482 & 17 \\
\hline 4 & 0,999999960007999 & 0,999999960007999 & 0,999999910026995 & 0,999999910026995 & 0,999999740070013 & 20 \\
\hline 5 & 0,999999960007999 & 0,999999960007999 & 0,999999999973012 & 0,999999910026995 & 0,999999830016014 & 23 \\
\hline 6 & 0,999999960007999 & 0,999999960007999 & 0,999999999973012 & 0,999999999973012 & 0,9999999919962024 & 26 \\
\hline
\end{tabular}

Table 15 Results of solving the problem of optimal reservation

\begin{tabular}{|c|c|}
\hline$l$ & $X_{S R C}^{(l)}$ \\
\hline 1 & $2,2,3,2$ \\
\hline 2 & $2,2,2,3,3,3$ \\
\hline 3 & $3,2,3,3,3,3,3$ \\
\hline 4 & $2.2,2,2,3,2,3,3,3,3$ \\
\hline 8 & $2,2,2,2,2,2,3,3,3,3,2,3,3,3,3,3$ \\
\hline
\end{tabular}

Table 16 The values of the components $X(L)$ of the state vectors CSEDP in SRC

\begin{tabular}{|c|c|c|c|c|c|c|c|c|c|c|c|c|c|c|c|c|c|c|}
\hline \multirow{2}{*}{$L$} & \multicolumn{16}{|c|}{$X(L)$} & \multirow{2}{*}{$V(L)$} & \multirow{2}{*}{$V_{\text {max }}$} \\
\hline & $m_{1}$ & $m_{2}$ & $m_{3}$ & $m_{4}$ & $m_{5}$ & $m_{6}$ & $m_{7}$ & $m_{8}$ & $m_{9}$ & $m_{10}$ & $m_{11}$ & $m_{12}$ & $m_{13}$ & $m_{14}$ & $m_{15}$ & $m_{16}$ & & \\
\hline 1 & 2 & 2 & 3 & 2 & - & - & - & - & - & - & - & - & - & - & - & - & 23 & 24 \\
\hline 2 & 2 & 2 & 2 & 3 & 3 & 2 & - & - & - & - & - & - & - & - & - & - & 46 & 48 \\
\hline 3 & 2 & 2 & 3 & 3 & 3 & 3 & 3 & - & - & - & - & - & - & - & - & - & 71 & 72 \\
\hline 4 & 2 & 2 & 2 & 2 & 2 & 2 & 3 & 3 & 3 & 3 & - & - & - & - & - & - & 94 & 96 \\
\hline 8 & 2 & 2 & 2 & 2 & 2 & 2 & 3 & 3 & 3 & 2 & 2 & 3 & 3 & 3 & 3 & 3 & 189 & $\begin{array}{c}19 \\
2\end{array}$ \\
\hline
\end{tabular}

The results of solving the problem of optimal reservation in the SRC, in the form of a set of state vectors of the reserved CSEDP, are presented in table 16.

Using the results of the solution, the problem of optimal reservation in SRC for the values $l=1,2,3,4,8$ (with the same initial data: $=1$ hour, $\lambda_{r}=10^{-4}[1 /$ hour $]$ ), which are presented in table 16, we will develop the corresponding mathematical models of reliability of CSEDP, as well as we will carry out the synthesis of real-time fault-tolerant structures of CSEDP.

Thus, on the basis of the results of solving the problem of optimal redundancy in SRC, mathematical models of fail-stability (of CSEDP for $l$ - byte machine words were developed. Using the research results, reliability structures were obtained, on the basis of which the structures of fault-tolerant CSEDPs were synthesized [15]. 


\section{CONCLUSION}

In the context of digitalization, it is necessary to improve methods of diagnosis and correction of errors in the system of residual classes as a basis for information security at the state level [16]. Modern methods and means of information and communication and digital technologies cannot fully ensure productive and reliable processing of ever-growing arrays of information in the economy. Digitization processes require a significant increase in the speed and reliability of economic data processing, which is possible through the use of new machine arithmetic, as the existing positional binary number system has shortcomings, and existing methods of unauthorized access, hacking attacks, viruses and other types of hacking based of using a binary position code. Therefore, it is necessary to search for opportunities to use such arithmetic, in which the data were protected, and the system itself was highly productive [17].

The results of solving the problem of optimal reservation gave a general answer about the degree of efficiency of the use of SRC to improve the fault tolerance of CSEDP. Based on the ideas of structural redundancy (reservation), the joint use of the properties allows us to synthesize a reliability CSEDP model in SRC corresponding to the dynamic redundancy model in the PNS [18]. In this case, the information computational paths $m_{1} \div m_{n}$ of CSEDP perform the functions of working elements, and paths $m_{n+1} \div m_{n+k}$ play the role of reserve elements bases of the SRC.

The results of research have shown that the use of SRC as a number systemof CSEDP the possibility of error correction in the dynamics of the computational process by adding small (and therefore more reliable than in positional processors) backup blocks and ensuring high active fault tolerance on the basis of the possibility of opera-tional reconfiguration of the structure of CSEDP.

Information security is of great importance for the vital interests of any state. The creation of a developed and secure environment is a necessary condition for the development of society and the state, which should be based on the latest automated technical means, as for the prompt execution of transactions, all services can be provided via the Internet [19]. The effectiveness of state regulatory policy in this aspect is measured by the ability to ensure the safe development of the national economy [20].

Every day the problem of information protection becomes more and more relevant. Various areas of our lives are computerized and therefore have a wide range of virus attacks and unauthorized intrusions. To counter external attacks, it is necessary not only to have effective means of protection, but also to know their system of operation, settings and weaknesses of operating systems.

\section{REFERENCES}

[1] Yanko, A.S., Glushko, A.D. Optimal reservation of data in the system of residual classes in the direction of ensuring information security of the national economy. Economics and Region, 4 (75), 2019, pp. 36-44. https://doi.org/10.26906/eip.2019.4(75).1814.

[2] Glushko, A.D. Directions of Efficiency of State Regulatory Policy in Ukrain. World Applied Sciences Journal. Pakistan: International Digital Organization for Scientific Information, 27 (4), 2013, pp. 448-453. https://doi.org/10.5829/idosi.wasj.2013.27.04.13656.

[3] Akushskii, I.Ya., Yuditskii, D.I. Machine Arithmetic in Residual Classes. Sov. Radio, Moscow, 1968.

[4] Krasnobayev, V., Koshman, S. and Mavrina, M. A method for increasing the reliability of verification of data represented in a residue number system. Cybernetics and Systems Analysis, vol. 50, Issue 6, 2014, pp. 969-976. https://doi.org/10.1007/s10559-014-9688-3. 
Conceptual Principles of Providing the Information Security of the National Economy of Ukraine in the Conditions of Digitalization

[5] Krasnobayev, V., Yanko, A. and Koshman, S. A Method for arithmetic comparison of data represented in a residue number system. Cybernetics and Systems Analysis, vol. 52, Issue 1, 2016, pp. 145-150. https://doi.org/10.1007/s10559-016-9809-2.

[6] Varnaliy, Z. S. Economic security: tut. K.: Knowledge, 2009, 647 p.

[7] Heiets, V. M. The concept of economic security of Ukraine. K.: Logos, 1999, 56 p.

[8] Yurkiv, N. Ya. Economic Security of the Real Sector of the Ukrainian Economy: Strategic Priorities and Theoretical and Methodological Principles of Providing: Monograph. Lviv: PAIS, 2012, 400 p. ISBN 978-966-1585-92-7.

[9] Krasnobayev, V., Kuznetsov, A., Yanko, A., Koshman, S., Zamula A. and Kuznetsova T. Data processing in the system of residual classes. Monograph. ASC Academic Publishing, 2019, 208 p. ISBN: 978-0-9989826-6-3 (Hardback), ISBN: 978-0-9989826-7-0 (Ebook).

[10] Krasnobayev, V., Koshman, S. A method for operational diagnosis of data represented in a residue number system. Cybernetics and Systems Analysis, vol. 54, Issue 2, 2018, pp. 336-344. https://doi.org/10.1007/s10559-018-0035- y.

[11] Kavun, S., Zamula, A., Mikheev, I. Calculation of expense for local computer networks. 4th International Scientific-Practical Conference Problems of Infocommunications. Science and Technology (PIC S\&T), Kharkov, 2017, pp. 146-151. https://doi.org/10.1109/INFOCOMMST.2017.8246369.

[12] Shu, S., Wang, Y., Wang, Y. A research of architecture-based reliability with fault propagation for software-intensive systems. Annual Reliability and Maintainability Symposium (RAMS), Tucson, AZ, 2016, pp. 1-6. https://doi.org/10.1109/RAMS.2016.7447984.

[13] Carlos Gomes Wille, E., Mincov Tenorio, M. Considering Packet Loss Probability in FaultTolerant OSPF Routing. IEEE Lat. Am. Trans., vol. 12, no. 2, 2014, pp. 248-255. https://doi.org/10.1109/TLA.2014.6749545.

[14] Harman, G., Shparlinski, I.E. Products of Small Integers in Residue Classes and Additive Properties of Fermat Quotients. International Mathematics Research Notices, vol. 2016, no. 5, pp. 1424-1446. https://doi.org/10.1093/imm/rnv182.

[15] Hodson, R. F. Real-Time Expert Systems Computer Architecture. CRC Press, 2018. https://doi.org/10.1201/9781351076203

[16] Onyshchenko, S., Yehorycheva, S., Furmanchuk, O., Maslii, O. Ukraine Construction Complex Innovation-Oriented Development Management. Proceedings of the 2nd International Conference on Building Innovations, 2019, pp. 687-700. https://doi.org/10.1007/978-3-03042939-3 68.

[17] Onyshchenko, V.O., Sivitska, S.P., Cherviak, A.V. Construction industry in Ukraine credit analysis. International Journal of Engineering and Technology (UAE), no. 7, 2018, pp. 280-284. https://doi.org/10.14419/ijet.v7i3.2.14420.

[18] Yadin, A. Computer Systems Architecture. Chapman and Hall/CRC, 2016, 467 p. https://doi.org/10.1201/9781315373287.

[19] Onyshshenko, S., Sivitska, S., Shapovalova, O., Cherviak, A. Information systems protection in financial institutions. International Journal of Engineering \& Technology, Vol 7, no 4.8, 2018, pp. 856 - 859. https://doi.org/10.14419/ijet.v7i4.8.28136.

[20] Glushko, A., Marchyshynets, O. Institutional provision of the state regulatory policy in Ukraine. Journal of Advanced Research in Law and Economics, ASERS Publishing House, Volume 9, Issue 3, 2018, pp. 941-948. https://doi.org/10.14505/jarle.v93(33).18. 